\title{
Structure of Al-Fe alloys synthesized from elemental powders by severe plastic deformation under high pressure
}

\author{
A. V. Dobromyslov ${ }^{\dagger}$, N. I. Taluts, V.P. Pilyugin \\ †Dobromyslov@imp.uran.ru \\ Institute of Metals Physics, Ural Branch of RAS, 18 S. Kovalevskaya Str., 620990, Ekaterinburg, Russia
}

\begin{abstract}
Methods of X-ray diffraction analysis, optical metallography, transmission and scanning electron microscopy have been used to study the phase state and structural evolution of binary Al-Fe alloys prepared from a mixture of elemental powders by severe plastic deformation under pressure. The Al-Fe alloys with iron contents ranging from 5 to 50 at. \% are produced by a mechanical alloying. The samples are processed up to 30 revolutions. Mechanically alloyed alloys are studied as a function of iron contents. The obtained results demonstrate that super saturated solid solution is formed during the mechanical alloying. It is revealed that the solid solubility of iron in aluminum has been extended up to $\sim 1$ at. $\%$ compared to the maximal value 0.025 at. $\%$ at $652^{\circ} \mathrm{C}$. It is established that the size of grains depends on the alloying metal content in the alloy and the degree of plastic deformation. After plastic deformation for 30 revolutions, the average grain size in the $\mathrm{Al}-10$ at.\% Fe alloy is $\sim 5-10$ $\mathrm{nm}$. Regions with an amorphous structure are observed in alloys at the iron content $>10$ at.\%. It has been revealed that the fracture surface stands in a certain causal relation with the iron content in the synthesized alloy: in the alloys $\mathrm{Al}-5$ at.\% $\mathrm{Fe}$ and $\mathrm{Al}-10$ at.\% Fe the fracture surface has traces of ductile fracture, and in the alloys with a higher iron content the fracture is brittle.
\end{abstract}

Keywords: Al-Fe alloys; mechanical alloying; pressure; structure; properties.

\section{Introduction}

At the present time, aluminum alloys find a wide application in various engineering fields. High strength properties of these materials are conditioned by alloying with $\mathrm{Cu}, \mathrm{Zn}, \mathrm{Mg}$ and Si. All these alloying additions are characterized by a comparatively high solubility in aluminum at high temperatures. The supersaturated solid solution, forming at high temperatures, decomposes at low temperatures with formation of various metastable phases, which leads to high service properties of ageing aluminum alloys. Unlike $\mathrm{Cu}, \mathrm{Zn}, \mathrm{Mg}$ and $\mathrm{Si}, d$-metals have a very low solubility in aluminum, which does not allow ageing to be used to improve the properties of alloys of aluminum with such metals. Therefore one of the most important tasks in developing the alloys of aluminum with various d-metals is to enhance their solubility in the a-phase of aluminum or produce such composite structures in which an alloying metal would be present in the form of small particles uniformly distributed in the aluminum crystal lattice. The methods of energy action on powder mixtures [1-13] are to the ways that enable one to produce such alloys. Among them, the most promising is the synthesis of alloys from elemental powders through the application of severe plastic deformation under high pressure in Bridgman's anvils [14-20]. Deformation of powders, unlike deformation of monolithic samples, significantly increases both the refinement degree of forming material and the kinetics of mechanodiffusion due to a considerable increase in the total area of interacting surfaces.
In addition, in the process of such mechanosynthesis both the pressure value and the deformation degree are characterized, which allows a good reproduction of the technology of the processes under development.

In the present work, a task has been set to synthesize alloys of the Al-Fe system from elemental powders of aluminum and iron, with an iron content up to 50 at.\%, through the application of severe plastic deformation under high pressure, and study their phase composition and structure.

\section{Experimental Procedures}

To synthesize the alloys, aluminum (99.99 wt.\%) and iron (99.96 wt.\%) powders with an average particle size of $\sim 50 \mu \mathrm{m}$ were taken. The alloys were synthesized using torsional straining of the powders mixture between Bridgman's cylindrical anvils under a pressure of $8 \mathrm{GPa}$. The number of turns of the rotating anvil varied from 1 to 30. Alloys of the following compositions were synthesized: $\mathrm{Al}-5$ at.\% $\mathrm{Fe}, \mathrm{Al}-10$ at.\% Fe, Al-15 at.\% Fe, Al-20 at.\% Fe, $\mathrm{Al}-25$ at.\% $\mathrm{Fe}, \mathrm{Al}-30$ at.\% $\mathrm{Fe}, \mathrm{Al}-35$ at.\% $\mathrm{Fe}, \mathrm{Al}-40$ at.\% $\mathrm{Fe} \mathrm{Al}-45$, at.\% Fe, Al-50 at.\% Fe. The synthesized alloys were investigated using X-ray diffraction analysis, optical metallography, transmission and scanning electron microscopy. X-ray diffraction analysis was performed on a DRON-3 diffractometer using $\mathrm{Cu} \mathrm{K}$-radiation and a graphite crystal monochromator. A Neophot-32 microscope and a Quanta 200 scanning electron microscope were 


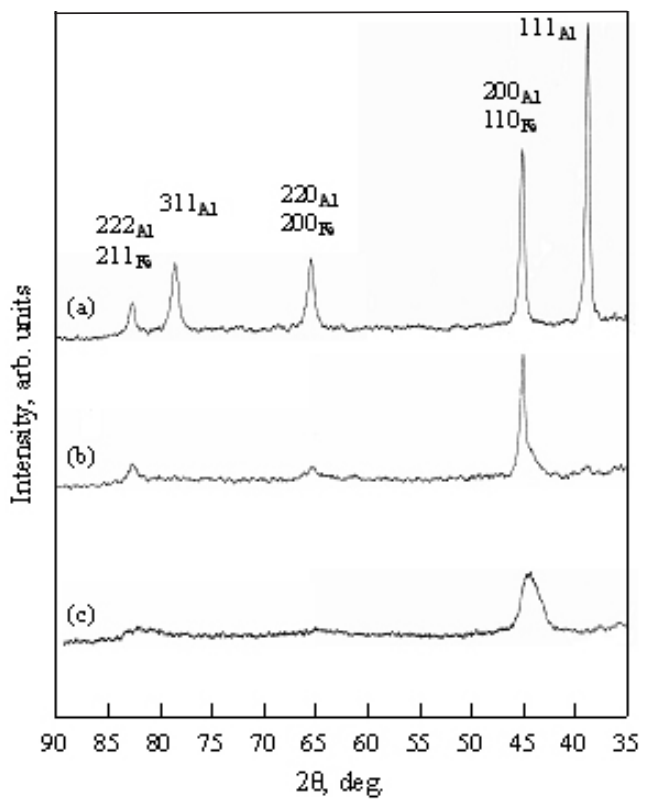

Fig. 1. X-ray diffraction patterns of $\mathrm{Al}$ - Fe alloys synthesized by severe plastic deformation under pressure: (a) $\mathrm{Al}$ - 5 at.\% Fe; $8 \mathrm{GPa}, 10$ revolutions; (b) $\mathrm{Al}$ - 35 at.\% Fe; $8 \mathrm{GPa}, 5$ revolutions; (c) $\mathrm{Al}$ - 50 at.\% Fe; 8 GPa, 5 revolutions.

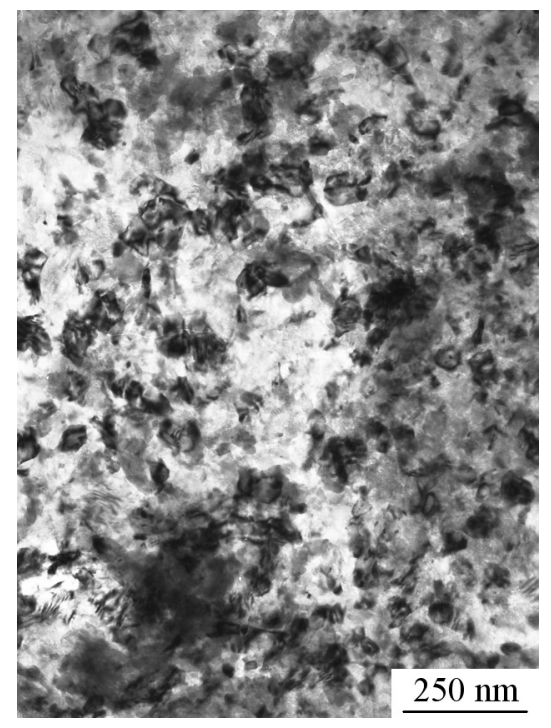

a

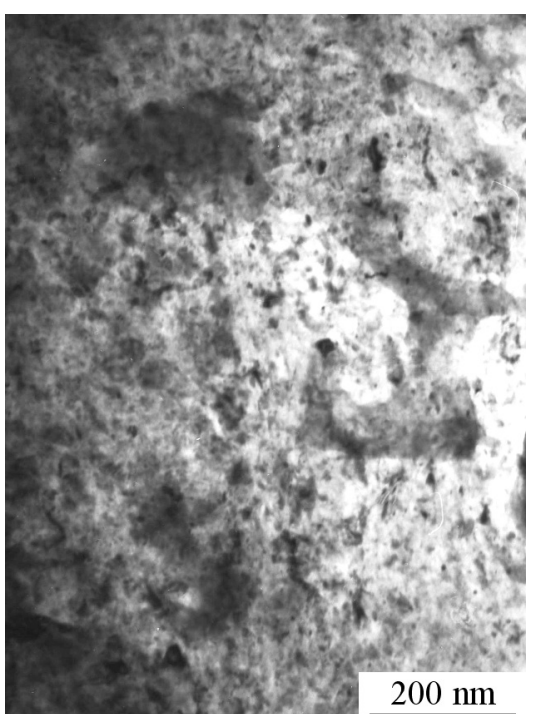

b employed to study the structure. A microstructural study was conducted on a JEM-200CX electronic microscope at an accelerating voltage of $160 \mathrm{kV}$.

\section{Results and discussion}

All the alloys synthesized from the elemental powders have a monolithic structure. It follows from the optical metallography data that the structure of the alloys essentially depends on the degree of plastic strain. After deformation processing for 1-2 revolutions, traces of extrusion processes are observed in the alloys structure, which manifested themselves in the presence of peculiar vortices and the regions of inhomogeneous plastic flow of the powder material. However, after 10 revolutions the alloy structures become practically homogeneous.

The X-ray diffraction analysis shows that X-ray diffraction patterns exhibit only the diffraction peaks of the $f c c$-phase. It is difficult to judge about the presence of pure iron in the alloys, which did not interact with aluminum during severe plastic deformation under pressure, due to the fact that the position of all the diffraction peaks of iron coincides with the

Fig. 2. Microstructure of $\mathrm{Al}-\mathrm{Fe}$ alloys synthesized by severe plastic deformation under pressure: (a) $\mathrm{Al}-5$ at. $\% \mathrm{Fe}$; 8 GPa, 30 revolutions; (b, c ) $\mathrm{Al}-10$ at.\% Fe, $8 \mathrm{GPa}, 30$ revolutions; (a, b) bright-field images, (c) dark-field image.

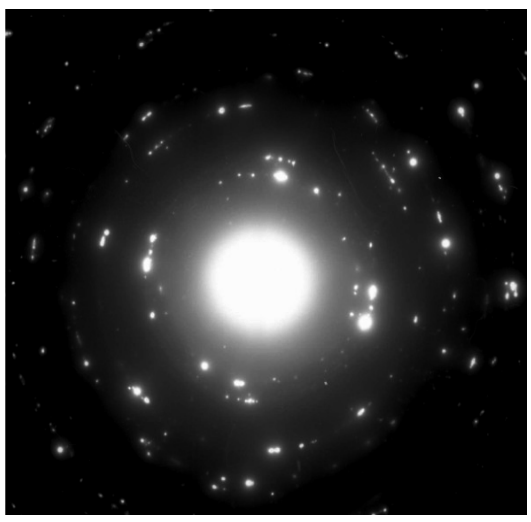

a

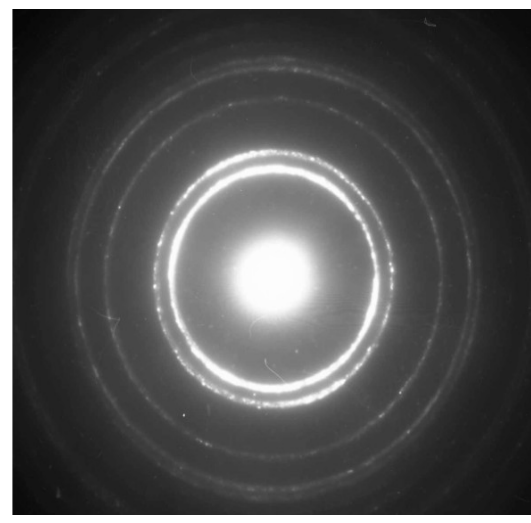

$\mathrm{b}$

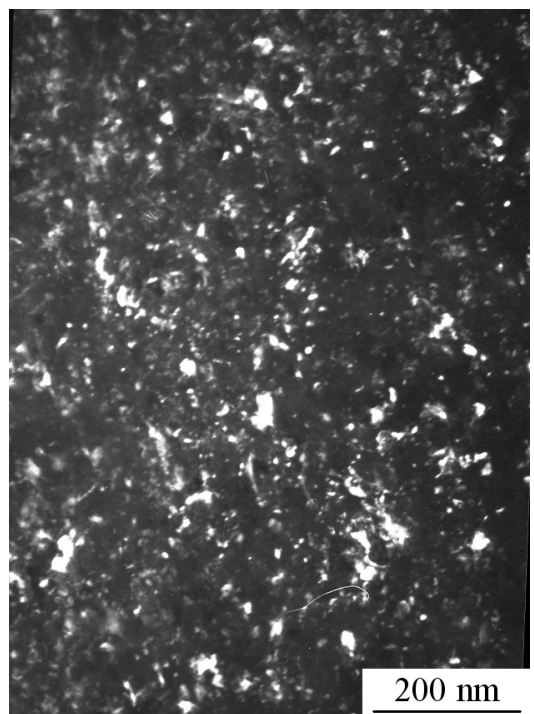

C

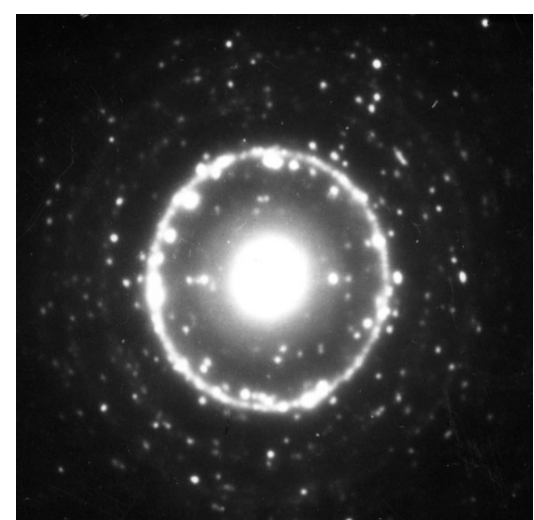

C

Fig. 3. Micro-electron diffraction patterns of $\mathrm{Al}-\mathrm{Fe}$ alloys synthesized by severe plastic deformation under pressure: (a) $\mathrm{Al}-5$ at.\% Fe; 8 $\mathrm{GPa}, 10$ revolutions; (b) $\mathrm{Al}-10$ at.\% $\mathrm{Fe}, 8 \mathrm{GPa}, 10$ revolutions; (c) $\mathrm{Al}-20$ at.\% $\mathrm{Fe}, 8 \mathrm{GPa}, 5$ revolutions. 


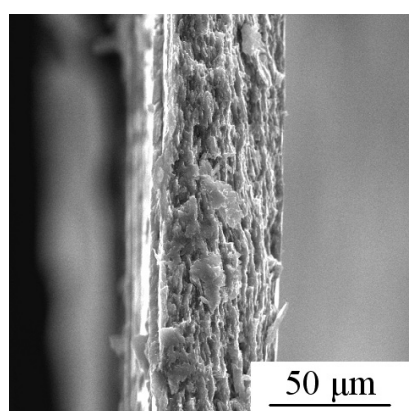

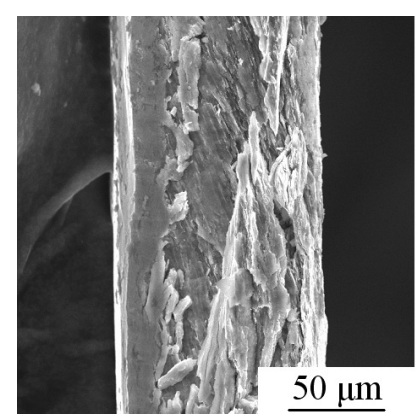

b

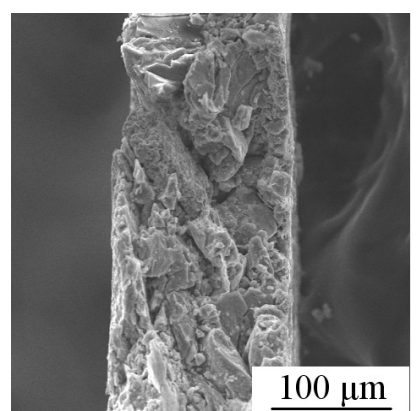

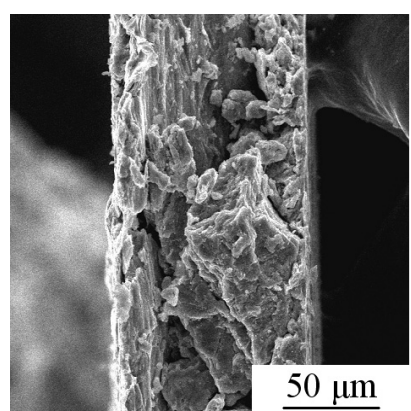

d

Fig. 4. View of fracture surface: (a) $\mathrm{Al}-5$ at.\% Fe; (b) $\mathrm{Al}-10$ at.\% Fe; (c) $\mathrm{Al}-30$ at.\% $\mathrm{Fe}$; (d) $\mathrm{Al}-50$ at.\% Fe.

position of some aluminum peaks. The analysis shows that the X-ray diffraction patterns of the synthesized alloys demonstrate a displacement of the aluminum diffraction peaks not coinciding with iron peaks towards larger angles $\theta$, which indicates iron solution in the aluminum crystal lattice. Calculation shows that the solubility of iron in aluminum totals $\sim 1$ at.\%, which is almost 40 times higher than the maximal solubility at $652^{\circ} \mathrm{C}$. Measurement of the iron content in aluminum regions made using an attachment for microanalysis in a scanning electron microscope yields the same value.

The X-ray diffraction patterns of the alloys with an iron content of over 10 at.\% illustrate a noticeable broadening of diffraction peaks (see Fig.1). A characteristic feature of the diffraction pattern is the appearance, close to the common line $200_{\mathrm{Al}}$ and $110_{\mathrm{Fe}}$, from the side of small angles, of a broad maximum indicating the formation of regions with an amorphous structure in the alloy. As the iron content grows higher than 25 at.\%, the intensity of the diffraction peaks decreases, except the common line $200_{\mathrm{Al}}$ and $110_{\mathrm{Fe}}$, which is the only observed quite often in the diffraction patterns of the alloy $\mathrm{Al}-50$ at.\% Fe.

The electron microscopy study shows that the structure of the alloys depends on both the degree of shear strain and the iron content in the initial mixture of powders. Due to the specifics of straining, at a small number of revolutions the alloy structure is more homogeneous in the periphery portion of the disk than in the layers located at the center of the disk. During mechanical alloying, the powder particles of aluminum and iron turn into long bands that form a peculiar lamellar structure. The width of such bands is 70 $\mathrm{nm}$ on the average.

With increasing shear strain, the thickness of such bands decreases, and the bands start to break into numerous fragments. The formation of a nanocrystalline structure takes place both at the boundaries of such fragments and within them. With increasing number of revolutions, the alloys' structure becomes more homogeneous. The average grain size in the $\mathrm{Al}-5$ at.\% Fe alloy after processing for 30 revolutions is about $10-15 \mathrm{~nm}$. A typical structure of such an alloy is presented in Fig.2a. In the majority of the electron diffraction patterns of the alloy $\mathrm{Al}-5$ at.\% Fe diffraction rings are absent, predominantly a large number of separate reflections are observed, some of which have an increased intensity (see Fig.3a). The round shape of reflections and the absence of ring blurring indicate possible processes of dynamic recrystallization during severe plastic deformation. In the dark-field images of such reflections, recrystallized grains are observed in the structure. Such grains normally have equilibrium boundaries, and they are evidently grains of aluminum that have not interacted with iron during severe plastic deformation. However, the quantity of such grains in the alloy is not large.

Figure $2 \mathrm{~b}$ and $2 \mathrm{c}$ present the bright-field and dark-field images of the structure of the alloy $\mathrm{Al}-10$ at.\% Fe processed for 30 revolutions. It is clearly visible that the dispersion of this alloy's structure is considerably higher than that of the alloy $\mathrm{Al}-5$ at.\% Fe. The average grain size in this alloy, calculated from the dark-field images, is $\sim 5-10 \mathrm{~nm}$. The diffraction pattern of this alloy undergoes a significant change. In the electron diffraction patterns mainly thin continuous rings are observed (see Fig.3b).

The structure of the alloys $\mathrm{Al}-20$ at.\% and $\mathrm{Al}-25$ at.\% has approximately the same appearance as the structure of alloys with a lower iron content. However, the diffraction pattern continues to change. The diffraction ring $200_{\mathrm{Al}}$, coinciding with the ring $110_{\mathrm{Fe}}$, broadens slightly and becomes continuous, while the ring $111_{\mathrm{Al}}$ broadens as well in some electron diffraction patterns and consists of a multitude of individual reflections in other electron diffraction patterns. The intensity of the common ring $200_{\mathrm{Al}}$ and $110_{\mathrm{Fe}}$ increases a lot, and the intensity of all the other rings significantly decreases. In a number of cases, the presence of only one ring corresponding to $200_{\mathrm{Al}}-110_{\mathrm{Fe}}$ (see Fig.3c) is observed.

Note should be made that in some electron diffraction patterns, alongside with diffraction rings from a polycrystalline alloy, a regular network of reflections was observed, indicating the formation of various iron aluminides in the process of mechanical alloying. It was reported earlier in literature that during processing of aluminum and iron powders in a planetary mill, the formation of iron aluminides with different structures was observed $[6,10,11,13]$. The analysis of the observed diffraction pattern did not allow us to identify it with any known iron aluminides, and due to an insufficient quantity of micro-electron diffraction patterns with different zone axes it was impossible to define their structure.

Apparently, such aluminides have a very small thickness, therefore during electron microscopy study only one or in some cases two reflection rows are observed in microelectron diffraction patterns. Thus, it was impossible to identify the type of the forming aluminide from the available 
electron diffraction patterns.

It has been established from the study of the fracture surface of the synthesized alloys that there is a certain correlation with the iron content: in the alloys $\mathrm{Al}-5$ at.\% $\mathrm{Fe}$ and $\mathrm{Al}-10$ at.\% $\mathrm{Fe}$ the fracture surface has traces of ductile fracture (see Fig.4a,b), and in the alloys with a higher iron content the fracture is brittle (see Fig.4c,d).

\section{Conclusions}

It follows from the obtained results that mechanical alloying does not lead to a significant increase in the solubility of iron in aluminum crystal lattice, which correlates with the data from the work [6]. Both the iron content in the initial mixture of powders and the degree of plastic strain have an effect on the grain size in the synthesized alloys. After plastic deformation processing for 30 turns the average grain size in the alloy $\mathrm{Al}-10$ at.\% $\mathrm{Fe}$ is $\sim 5-10 \mathrm{~nm}$. In the process of mechanical alloying, formation of both regions with an amorphous structure and a small quantity of iron aluminides with an imperfect structure takes place.

This work was performed under state assignment No. 01201463327 on the topic "Deformation" with the support of Russian Foundation for Basic Research (project no 14-0300539).

The electron microscopy study was performed on a Quanta 200 scanning electron microscope and a JEM-200CX transmission electron microscope at the Center of Electron Microscopy of the Testing Center for Nanotechnologies and Advanced Materials at the Institute of Metals Physics, Ural branch of Russian Academy of Sciences.

\section{References}

1. D. K. Mukhopadhyay, C. Suryanarayana, F. H. (Sam) Froes. Metall. and Mater. Trans. A26, 1939 (1995).

2. F. Cardellini, V. Contini, R. Gupta, G. Mazzone,
A. Montone, A. Perin, G. Pricipi. J. Mater. Sci. 33, 2519 (1998).

3. I. S. Ahn, K-C. Jung, S. S. Kim, Y. Y. Kim. Metals and materials. 5, 619 (1999).

4. R. A. Dunlap, J. R. Dahn, D. A. Eelman, G. R. MacKay. Hyperfine Interactions. 116, 117 (1998).

5. L. Jinxin, P. Hua, J. Wei, Z. Lijing, T. Meikuang. J. of Mater. Sci. Letters. 18, 1743 (1999).

6. M. M. Rajath Hegde, A. O. Surendranathan. Powder Metall. Met. Ceram. 48, 641 (2009).

7. S. S. Nayak, M. Wollgarte, J. Banhart, S. K. Pabi, B. S. Murty. Mater. Sci. Eng. A527, 2370 (2010).

8. S. Zhou, W. Wang. Rare metals. 29, 220 (2010).

9. M. Tavaoosi, F. Karimzadeh, M. H. Enayati, S.-H. Joo, H. S. Kim. J. Mater. Sci. 46, 7633 (2011).

10. E. P. Yelsukov, A. L. Ul'yanov, A. V. Protasov, D. A. Kolodkin. Phys. Met. Metallogr. 113, 635 (2012).

11. E. P. Elsukov, A. V. Protasov, A. L. Uluanov, D. A. Kolodkin. Phys. Met. Metallogr. 114, 148 (2013).

12. T. Bachaga, R. Daly, L. Escoda, J. J. Suñol, M. Khitouni. Metall and Mater. Trans. A44, 4718 (2013).

13. B. Abar, M. Gogebakan, S. Ozcan, S. Kerli. J. of Korean Physical Society. 65, 664 (2014).

14. A. V. Dobromyslov, R. V. Churbaev, V. A. Elkin, T. L. Trenogina. Scripta Mater. 41, 1015 (1999).

15. A. V. Dobromyslov, R. V. Churbaev, V. A. Elkin. Phys. Met. Metallogr. 87, 140 (1999).

16. A. V. Dobromyslov, E. K. Dolgikh, T. L. Trenogina, R. V. Churbaev. Russian metallurgy (Metally). 5, 43 (2005).

17. A. V. Dobromyslov, R. V. Churbaev. Int. J. Mod. Phys. B24, 722 (2010).

18. C. Xu, Z. Horita, T. G. Langdon. Mater Trans. 51, 2 (2010).

19. K. Edalati. Z. Horita, H. Fujiwara, K. Ameyama. Metall and Mater. Trans. 41 A, 3308 (2010).

20. J. M. Cubero-Sessin, Z. Horita. Metall and Mater. Trans. A43, 5182 (2012). 